\title{
Analysis of Macro and Micronutrients in Soils from Palestine Using Ion Exchange Membrane Technology
}

\author{
Zaher Barghouthi ${ }^{1}$, Sameer Amereih ${ }^{2}$, Basel Natsheh ${ }^{2}$, Mazen Salman $^{2 *}$ \\ ${ }^{1}$ Dpartment of Natural Resources Research, National Agricultural Research Center (NARC), Jenin, Palestine; ${ }^{2}$ Palestine Technical \\ University-Kadoorie, Tulkarm, Palestine. \\ Email: *salman_mazen@daad-alumni.de
}

Received December $15^{\text {th }}, 2011$; revised January $16^{\text {th }}, 2012$; accepted January $30^{\text {th }}, 2012$

\begin{abstract}
Ion Exchange membrane technology (IEM) is a method that allowed a single extraction process and a single subsequent measurement of different elements that are available in soil. The values of the available forms of the different macroand micronutrients obtained by IEM extraction were compared with the values of the soluble form obtained by conventional extraction methods. In surface soil sample, the concentrations of available potassium, nitrate, phosphate, iron and boron were $37.7 \mathrm{mg} \cdot \mathrm{kg}^{-1}, 17.5 \mathrm{mg} \cdot \mathrm{kg}^{-1}, 3.6 \mathrm{mg} \cdot \mathrm{kg}^{-1}, 171.0 \mu \mathrm{g} \cdot \mathrm{kg}^{-1}$, and $4.2 \mu \mathrm{g} \cdot \mathrm{kg}^{-1}$ respectively were greater than that of soluble forms of the same elements which were $7.0 \mathrm{mg} \cdot \mathrm{kg}^{-1}, 9.2 \mathrm{mg} \cdot \mathrm{kg}^{-1}, 0.4 \mathrm{mg} \cdot \mathrm{kg}^{-1}, 109.0 \mu \mathrm{g} \cdot \mathrm{kg}^{-1}$, and $1.9 \mu \mathrm{g} \cdot \mathrm{kg}^{-1}$ respectively.
\end{abstract}

Keywords: Ion Exchange Membrane; Available Ions; Soil; Nutrients; Palestine

\section{Introduction}

Soil is a diverse complex that can be defined as a mixture of minerals and organic materials, which are capable of supporting plant life [1,2]. Soil contains 13 out of 16 different elements essential for plant growth [3]. However, only small amounts of nutrients are available for plants [4]. Nutrients become available through mineral weathering and through decomposition of organic matter into inorganic mineral which are absorbed by plants in the form of ions [2,4,5]. Traditionally, an assessment of the nutrient status in the soil requires a separate extraction and measurement process for most elements; this is costly process in terms of both time and labor [6]. In the last decades Ion exchange resin has been used to assess the availability of plant nutrients where anion and cation exchange resins are used in numerous ways in soil and plant analysis $[7,8]$. The method simulates removing ions from soil by plant roots to prevent equilibrium of ions between the solid and the solution phases $[9,10]$. A major problem in using bead resins is the difficulty in their separation from the soil following the extraction $[9,11]$.

Ion exchange membrane technique (IEM) was developed as an alternative to chemical extraction methods to measure nutrients bioavailability $[10,11]$. In addition to its simplicity, rapidness and accuracy compared to other existing methods, the technique was found to be highly

"Corresponding author. suitable for soil testing because multi-element in soil can be tested $[9,11]$. Other advantages of IEM include greater sensitivity to environmental conditions, the potential ability to mimic nutrient uptake by roots, no diffusion problem due to its flat structure and minimal disturbance to soil structure [12]. IEM involves disaggregation of soil by shaking in water during 15 minutes with a glass marble, the elements transfer from the soil to the AEM and CEM during a 16 hours shaking period, removing of the membrane from the soil, and finally extracting the elements from the membrane (elution). IEM extraction method allow single extraction process and a single subsequent measurement of the soil available nitrate, phosphate, sulfate by IC, calcium, magnesium, total phosphorous, and heavy metals by inductive coupled plasma (ICP), sodium and potassium by flame photometer, and ammonium by UV/ VIS.

Commercial anion exchange resin are generally found in the chloride $\left(\mathrm{Cl}^{-}\right)$ion form while cation resin are usually commercialized in the hydrogen $\left(\mathrm{H}^{+}\right)$ion form [11]. The aim of this work is to use IEM technology for simultaneous determination of soluble and available forms of plant micro and macronutrients in surface and subsurface Palestinian soils.

\section{Materials and Methods}

\subsection{Materials}

Anion exchange membrane (AEM) and cation exchange 
membrane (CEM) were provided by BDH (55164-2S and 55165-2U, respectively). Except where stated, all chemicals were of analytical reagent grade. Distilled water $(18.2 \mathrm{M} \Omega \cdot \mathrm{cm})$ was used for ion chromatography (IC) measurements.

\subsection{Soil Samples}

Soil samples were collected from two depths $(0-30 \mathrm{~cm}$ and $30-60 \mathrm{~cm}$ ) from the agricultural station, National Agriculture Research Center (NARC), Jericho, in the Jordan Valley in the eastern side of the West Bank. The dominant soil texture in Jericho is sandy loam [13]. The $\mathrm{pH}$ of the surface soil samples was measured after suspending the soil in water $(1: 1 \mathrm{w} / \mathrm{v})$. The samples were air-dried and sieved using $0.3 \mathrm{~mm}$ sieve.

\subsection{Extraction of Nutrients}

Soil samples (10 g each) were transferred to 250-ml Erlenmeyer flask containing $100 \mathrm{ml}$ of double distilled water. Each sample was shaken for 30 minutes at $100 \mathrm{rpm}$ on a rotary shaker. The solution was filtered using Whatman \#1 filter paper and the filtrate was then passed through $0.2 \mu \mathrm{m}$ filters.

\subsection{Extraction of Available Form of Nutrients}

CEM and AEM sheets were cut into strips $(2 \times 6.25 \mathrm{~cm})$. Two strips of CEM and another two strips of AEM were dipped in 250-ml Erlenmeyer flask containing $10 \mathrm{~g}$ of soil dissolved in $100 \mathrm{ml}$ of distilled water $(18.2 \mathrm{M} \Omega \cdot \mathrm{cm})$. The flask was placed on shaker at $100 \mathrm{rpm}$ for $16 \mathrm{~h}$. Ions were then eluted by shaking the strips in $20 \mathrm{ml}$ of $0.1 \mathrm{M}$ $\mathrm{HCl}$ for $3 \mathrm{~h}$ at $100 \mathrm{rpm}$. The eluent was taken for ions instrumental measurements and the strips were regenerated in $100 \mathrm{ml}$ sodium bicarbonate $(0.5 \mathrm{M})$ on electronic shaker ( 2 hours, $100 \mathrm{rpm}$ ) and stored in deionized water prior to be reused.

\subsection{Total Amount of Nutrients}

The total amount of sodium, potassium, calcium, magnesium was determined by digesting soil sample using Microwave Accelerated Reaction System Model MARS 5. The soil $(0.5 \mathrm{~g})$ was suspended in $10 \mathrm{ml}$ distilled water containing concentrated $\mathrm{HNO}_{3}(5 \mathrm{ml}), \mathrm{HF}(4 \mathrm{ml})$, and $\mathrm{HCl}$ $(1 \mathrm{ml})$ in digestion vessel. Digestion was done for $20 \mathrm{mi}-$ nutes at $210^{\circ} \mathrm{C}$. After that $30 \mathrm{ml}$ of $30 \%$ boric acid were added to each vessel and the digestion was continued for 5 minutes at $210^{\circ} \mathrm{C}$.

\subsection{Extractable Sodium and Potassium}

Sodium and potassium were extracted according to the method of Richards 1954 [14]. Five grams of soil were suspended in $33 \mathrm{ml}$ of ammonium acetate in $100 \mathrm{ml}$ elementary flask and shacked for five minutes at $100 \mathrm{rpm}$. Extract was filtered through Whatman \#1 filter paper and transferred to $100 \mathrm{ml}$ volumetric flask. The volume of the extract was adjusted to $100 \mathrm{ml}$ with ammonium acetate solution, and filtered by $0.2 \mu \mathrm{m}$ filter [14].

\subsection{Instrumental Analysis}

Soluble, available, extractable, and total potassium and sodium forms were measured using Jenway flame photometer (Clinical PFP7). The amount of potassium and sodium in $\mathrm{mg} \cdot \mathrm{kg}^{-1}$ was determined according to a calibration curve of potassium and sodium respectively. The VARIAN VISTA-Charged Coupled Device Axial simultaneous Inductively Coupled Plasma-Atomic Emission Spectrometer (VISTA CCD-AES) with concentric nebuliser was used for the analysis of soluble, available and total calcium, magnesium, phosphorous, and heavy metals. Anions including nitrate, sulfate, and phosphate were measured using ion exchange chromatography (IC) system (Dionex 500) consisting of GP50 gradient pump, ED 40 electrochemical detector, and anion self regenerating suppressor. The stationary phase was IonPac AS11-HC analytical column, $2 \mathrm{~mm}(\mathrm{P} / \mathrm{N}$ 52961) while the mobile phase was $30 \mathrm{mM}$ hydroxide solution (BAKER ANALYZED Reagent) with constant flow at $0.38 \mathrm{ml} \cdot \mathrm{min}^{-1}$.

Soluble and available ammonium was determined according to Berthelot analytical procedure $[15,16]$ using PERKIN ELMER UV/VIS Spectrophotometer. Untritronic-OR (Selecta $\mathrm{P}$ ) thermostat was used as an electronic shaker. Soil pH was measured by 3310 JENWAY pH meter.

\section{Results and Discussion}

In past few decades, soil testing has been plagued by many problems that defy accuracy. These problems can be overcome using IEM methodology where the amount of recently nutrients that are available to the plants can be determined.

\subsection{Macronutrients}

\subsubsection{Potassium}

Potassium is an essential macronutrient for plant growth and development as well as for many plant functions [17, 18]. Testing potassium availability in soil plays the major role in estimating fertilization requirements. Potassium has four soil forms: solution, exchangeable, non-exchangeable, and mineral. The water soluble and exchangeable forms represent the available fraction of potassium. Whereas non exchangeable and mineral potassium forms are known to be slowly available unavailable [19]. Potassium availability is a complex situation; depletion of one form shifts the equilibrium between forms to replenish it (i.e. 
Non-Exchangeable $K \leftrightarrow$ Exchangeable $K \leftrightarrow$ Soil Solution). Potassium uptake by plants is governed by the rate of transport from the bulk soil to the root via diffusion [20]. It is expedient to measure a parameter that is closely related to diffusion. This might be achieved by measuring the concentration of soil potassium in the solution and exchangeable forms.

Figure 1 shows the amount of potassium in soluble, exchangeable, extractable, and available forms measured in soil samples at $0-30$ and $30-60 \mathrm{~cm}$ sub surfaces. Extractable potassium represents the available form which was measured by using ammonium acetate extraction method [14]. In some soils (e.g. calcareous) can be estimated as the sum of the soluble and exchangeable forms of potassium [21]. In this study the exchangeable potassium (29.3 $\left.\mathrm{mg} \cdot \mathrm{kg}^{-1}\right)$ was calculated from the difference between the extractable $\left(36.3 \mathrm{mg} \cdot \mathrm{kg}^{-1}\right)$ and the soluble $(7$ $\mathrm{mg} \cdot \mathrm{kg}^{-1}$ ) forms. Available potassium was measured using IEM extraction. The available potassium form reflects soluble and exchangeable forms. Our results showed that the available potassium which was measured using the IEM in surface and subsurface soil samples was 37.7 and $27.3 \mathrm{mg} \cdot \mathrm{kg}^{-1}$, respectively. The total potassium in both samples measured using flame photometer was $167 \pm 2.7$ and $172.4 \pm 3.1 \mathrm{mg} \cdot \mathrm{kg}^{-1}$ respectively.

\subsubsection{Nitrogen}

In terms of its requirement and management in the field, nitrogen is the most important nutrient for all crop plants [22]. The availability of nitrogen is closely associated with plant productivity $[23,24]$. Nitrogen is used by plants in two forms, ammonium $\left(\mathrm{NH}_{4}^{+}-\mathrm{N}\right)$ and nitrate $\left(\mathrm{NO}_{3}^{-}-\mathrm{N}\right)$ [25]. Nitrate is the dominate form of mineral nitrogen available for plant use $[26,27]$. The sum of the two forms constitutes the pool of plant-available nitrogen [21]. Several laboratory methods have been developed to assess nitrate availability. Most of these methods are insensitive to environmental factors that influence the soil nitrogen such as temperature and moisture [12]. IEM is a suitable alternative to overcome environmental sensitivity conditions. In the present work, both soluble and available forms of nitrate were extracted by IEM and measured by ion exchange chromatography (IC) using Dionex 500 system. Soluble and available forms of ammonium were measured colorimetrically using spectrophotometer. The amount of soluble and available nitrate and ammonium are given in Table 1. Our results revealed that the available amount of nitrate and ammonium in both surface and subsurface soil were greater than that of the soluble amount.

\subsubsection{Phosphorous}

The concentration of available form of phosphorous in soil is very low [21]. Determination of index of available

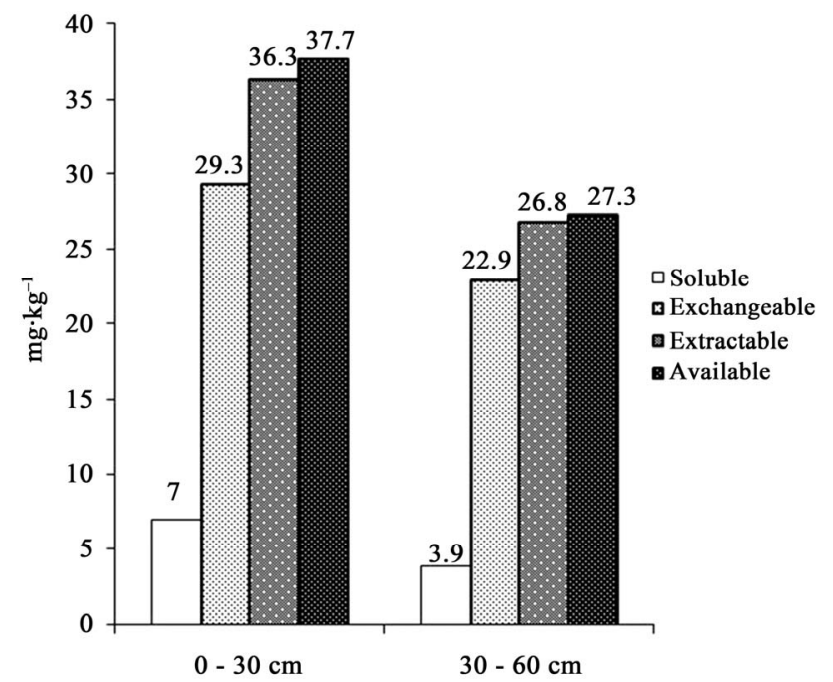

Figure 1. Soluble, exchangeable, extractable, and available forms of potassium in surface $(0-30 \mathrm{~cm})$ and subsurface $(30-60 \mathrm{~cm})$ soil samples measured by flame photometer in $\mathrm{mg} \cdot \mathrm{kg}^{-1}$. The value of each form in the figure is the average of nine replicates.

Table 1. Soluble and available forms of macronutrients in surface $(0-30 \mathrm{~cm})$ and subsurface $(30-60 \mathrm{~cm})$ soil in $\mathrm{mg} \cdot \mathrm{kg}^{-1}$. Each value in the table is the average for nine replicates.

\begin{tabular}{cccccc}
\hline & \multicolumn{2}{c}{ Soluble } & \multicolumn{2}{c}{ Available } & Total \\
\hline & $0-30(\mathrm{~cm})$ & $30-60(\mathrm{~cm})$ & $0-30(\mathrm{~cm})$ & $30-60(\mathrm{~cm})$ & \\
\hline Nitrate & $9.2 \pm 0.2$ & $5.6 \pm 0.1$ & $17.5 \pm 0.3$ & $10.2 \pm 0.1$ & 42.5 \\
Ammonium & $3.6 \pm 0.3$ & $3.1 \pm 0.2$ & $5.0 \pm 0.4$ & $3.5 \pm 0.3$ & 15.2 \\
Phosphate & $0.4 \pm 0.1$ & $0.22 \pm 0.04$ & $3.6 \pm 0.2$ & $2.9 \pm 0.2$ & 7.12 \\
Sulfate & $21.5 \pm 0.3$ & $9.7 \pm 0.2$ & $76.2 \pm 1.2$ & $44.7 \pm 1.4$ & 152.1 \\
Calcium & $20.4 \pm 0.5$ & $16.5 \pm 0.2$ & $69.5 \pm 2.1$ & $69.8 \pm 1.3$ & 176.2 \\
Magnesium & $5.6 \pm 0.3$ & $4.8 \pm 0.1$ & $11.9 \pm 0.3$ & $12.1 \pm 0.2$ & 34.4 \\
\hline
\end{tabular}

phosphorous is still a matter of interest [25]. The pool of bioavailable phosphorous is indexed by extraction of a portion of labile pool of inorganic phosphorous using chemical extractants such as Bray 1, Mehlich 1 or 3, and Olsen's solution $[10,28]$. In the present work, the available form of phosphate was tested (Table 1). The amount of phosphate available, in surface and subsurface soils, which was measured using IC system was $3.6 \mathrm{mg} \cdot \mathrm{kg}^{-1}$ and $2.9 \mathrm{mg} \cdot \mathrm{kg}^{-1}$ respectively. The low values of phosphate indicate phosphorous deficiency. It is well known that phosphorous is considered deficient when the concentration of available form of phosphorous is less than $6.0 \mathrm{mg} \cdot \mathrm{kg}^{-1}$.

\subsubsection{Sulfur}

Sulfate is one of the most commonly monitored anions in 
soils and natural waters. In soil extracts, sulfate is a measure of the available sulfur status [29]. Sulfate is subjected to leaching due to its high solubility. Therefore, it is usually found at variable depths. Our data reveal that the available amount of sulfate is greater than that of the so- luble amount (Table 1).

\subsubsection{Calcium and Magnesium}

Calcium and magnesium are available as exchangeable cations $\left(\mathrm{Ca}^{2+}\right.$ and $\left.\mathrm{Mg}^{2+}\right)$. The amount available of both elements is importantly related to mineral weathering and degree of leaching [30].

In the present work the different fractions of calcium and magnesium were measured using ICP instrumental system. The available fractions of both calcium and magnesium, in the surface and subsurface soils, were greater than that of the soluble forms. Compared to calcium, magnesium is less strongly absorbed to cation exchange sites. Thus much less available magnesium exists in soils and magnesium deficiencies have been observed frequently. The total amounts in the surface and subsurface soils of calcium were $2142.0 \pm 4.9 \mathrm{mg} \cdot \mathrm{kg}^{-1}$ and $2120.0 \pm 14.8$ $\mathrm{mg} \cdot \mathrm{kg}^{-1}$, respectively and the amounts of magnesium were $165.6 \pm 1.6 \mathrm{mg} \cdot \mathrm{kg}^{-1}$ and $160.9 \pm 4.8 \mathrm{mg} \cdot \mathrm{kg}^{-1}$, respectively.

\subsection{Micronutrients}

The $\mathrm{pH}$ is a key factor that affects the availability of the micronutrient. Except for molybdenum, availability of micronutrients decreases at higher $\mathrm{pH}$ and increased soil calcareousness due to adsorption precipitation reactions [21, 31]. It was found that the $\mathrm{pH}$ of soil under investigation was around 8. In high acidic soils, there is a relative abundance of iron, manganese, zinc, and copper ions, which are considered to be toxic to plants. In the present work, IEM was used successfully to determine the amount (in $\mu \mathrm{g} \cdot \mathrm{kg}^{-1}$ ) of micronutrients cations including soluble and available forms of iron, manganese, cupper, and zinc in both surface and subsurface soils (Figure 2). Cobalt cation was not detected in the soil under investigation. Our results indicated that the concentration of micronutrients in surface soils was lower than that in the subsurface soil samples (Figure 2).

Unlike cations, micronutrient anions are quite different chemically, thus little similarity would be expected in their reaction with soil. Boron was measured efficiently by IEM. The soluble and available boron in surface soil samples was $1.9 \pm 0.3 \mu \mathrm{g} \cdot \mathrm{kg}^{-1}$ and $4.2 \pm 0.3 \mu \mathrm{g} \cdot \mathrm{kg}^{-1}$, respectively, while soluble and available boron in subsurface soils was $1.7 \pm 0.2 \mu \mathrm{g} \cdot \mathrm{kg}^{-1}$ and $3.2 \pm 0.1 \mu \mathrm{g} \cdot \mathrm{kg}^{-1}$, respectively. Results of the current work demonstrated that the concentration of boron is within acceptable range for plant growth. In fact, when soil boron levels are less than $0.5 \mu \mathrm{g} \cdot \mathrm{kg}^{-1}$, deficiency is likely to occur for most crops. However, toxicity may occur when boron levels are greater than $5.0 \mu \mathrm{g} \cdot \mathrm{kg}^{-1}$ [21]. The total amounts of iron in surface and subsurface soils were $270.5 \pm 1.8$ and $265.1 \pm 4.4 \mu \mathrm{g} \cdot \mathrm{kg}^{-1}$, and the concentrations of manganese were $4.8 \pm 0.1$ and $4.6 \pm 0.1 \mu \mathrm{g} \cdot \mathrm{kg}^{-1}$ respectively. Therefore, small fraction from the total amount of micronutrients is available to plants.

\subsection{Sodium and Some Heavy Metals}

The measured values of soluble, exchangeable, extractable, and available forms of sodium in surface and subsurface soil samples are given in Figure 3. Extractable sodium $\left(139.4 \mathrm{mg} \cdot \mathrm{kg}^{-1}\right)$ represents the available form which can be measured using ammonium acetate extraction method [14], while exchangeable sodium $\left(83 \mathrm{mg} \cdot \mathrm{kg}^{-1}\right)$ was calculated as the difference between the extractable and the soluble forms. Total soil sodium was determined using the conventional ammonium acetate extraction method

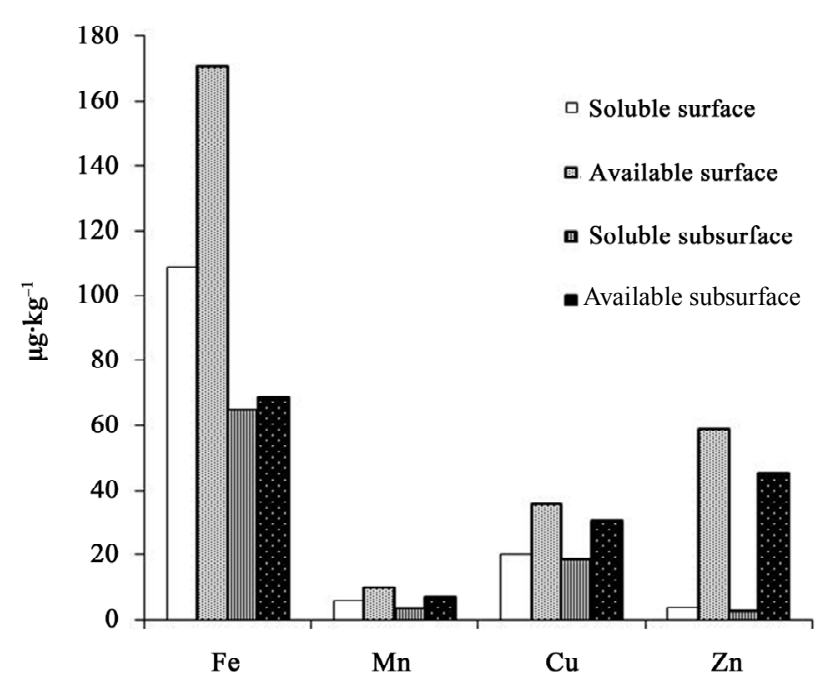

Figure 2. Soluble and available iron, manganese, copper, and zinc in surface and subsurface soils measured by ICPAES in $\mu g \cdot \mathrm{kg}^{-1}$.

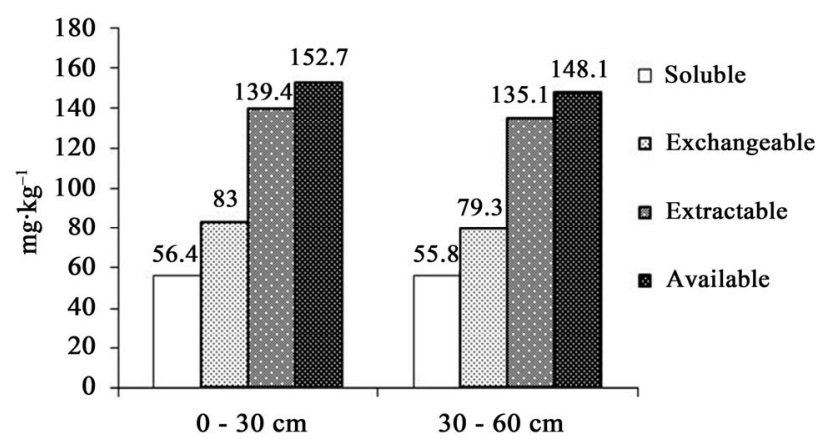

Figure 3. Soluble, exchangeable, extractable and available forms of sodium in surface and subsurface soil samples measured by flame photometer in $\mathbf{~ m g} \cdot \mathrm{kg}^{-1}$. Each value is the average for nine replicates. 


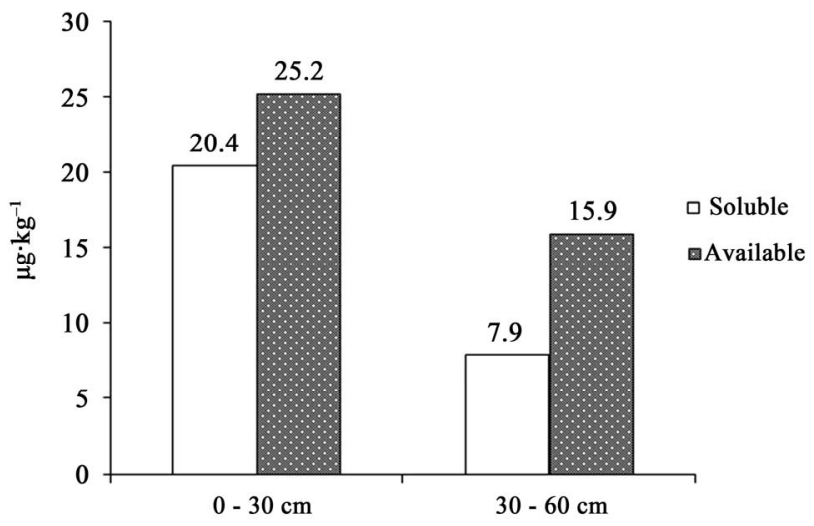

Figure 4. Soluble and available forms of chromium in different soil depths measured by ICP in $\mu \mathrm{g} \cdot \mathrm{kg}^{-1}$.

(Figure 3). However, this fraction can be determined more accurately by IEM extraction method.

Interestingly, the availability of heavy metals was predicted by applying the IEM (Figure 4). Chromium was detected in surface and subsurface soils.

\section{Conclusion}

IEM method allowed a single extraction and a single subsequent measurement of the concentrations of the available forms of the different macro- and micro-nutrients. The assessment of plant available nutritional ions using IEM may be superior to the standard chemical extractions. The exchangeable quantity of nutrients, which can relatively easily mobilized or mineralized during the growing season, is included in IEM extraction. This leads to better evaluation of the exactly amount of the fertilizer needed for the growing crops. There are no significant differences between available potassium and sodium measured by IEM or that measured by the conventional ammonium acetate extraction. The available amounts of different ions in standard soil sample were measured using IEM extraction method, and the results are in good agreement with that measured by the conventional methods.

\section{Acknowledgements}

The authors thank Prof. Mustafa Khamis and Prof. Magdy el-Dakiky for their suggestions and helpful discussions. Authors also thank the staff of the Center for the Chemical and Biological Research in Al-Quds University for their technical assistance. Special thanks are due to Mr. Azmi Saleh, Palestine Technical University (PTUK) for his constructive and objective comments on the manuscript.

\section{REFERENCES}

[1] A. S. Ayoub, B. A. McGaw, C. A. Shand and A. J. Midwood, "Phytoavailability of $\mathrm{Cd}$ and $\mathrm{Zn}$ in Soil Estimated by Stableisotope Exchange and Chemical Extraction," Plant and Soil, Vol. 252, No. 2, 2003, pp. 291-300. doi:10.1023/A:1024785201942

[2] N. C. Brady, "The Nature and Properties of Soils," Macmillan Publishing Company, New York, 1990.

[3] P. H. Raven, R. B. Linda and B. J. George, "Environment," Saunders College Publishing, Orlando, 1995.

[4] E. O. McLean and M. E. Watson, "Soil Measurements of Plant-Available Potassium," In: R. D. Munson, Ed., Potassium in Agriculture, Soil Science Society of America, Madison, 1985, pp. 227-308.

[5] R. Durand, N. Bellon and B. Jaillard, "Determining the Net Flux of Charge Released by Maize Roots by Directly Measuring Variations of the Alkalinity in the Nutrient Solution," Plant and Soil, Vol. 229, No. 2, 2001, pp. 305-318. doi:10.1023/A:1004860326936

[6] M. J. McLaughlin, P. A. Lancaster, P. W. G. Sale, N. C. Uren and K. I. Peverill, "Use of Cation/Anion Exchange Membranes for Multi-Element Testing of Acidic Soils," Plant and Soil, Vol. 155-156, No. 1, 1993, pp. 223-226. doi:10.1007/BF00025024

[7] K. J Greer and J. J. Schoenau, "A Rapid Method for Assessing Sodicity Hazard Using a Cation Exchange Membrane," Soil Technology, Vol. 8, No. 4, 1996, pp. 287-292. doi:10.1016/0933-3630(95)00025-9

[8] R. R. Schnabel, "Nitrate and Phosphate Recovery from Anion Exchange Resins," Communications in Soil Science and Plant Analysis, Vol. 26, No. 3-4, 1995, pp. 531-540. doi:10.1080/00103629509369316

[9] P. Qian, J. J. Schoenau and W. Z. Huang, "Use of Ion Exchange Membranes in Routine Soil Testing," Communications in Soil Science and Plant Analysis, Vol. 23, No. 15-16, 1992, pp. 1791-1804. doi: $10.1080 / 00103629209368704$

[10] S. Sato and N. B. Comerford, "Assessing Methods for Developing Phosphorous Desorption Isotherms from Soils Using Anion Exchange Membranes," Plant and Soil, Vol. 279, No. 1-2, 2006, pp. 107-117. doi:10.1007/s11104-005-0437-2

[11] M. B. Turrion, J. F. Gallardo and M. I. Gonzalez, "Extraction of Soil-Available Phosphate, Nitrate, and Sulphate Ions Using Ion Exchange Menbranes and Determination by Ion Exchange Chromatography," Communications in Soil Science and Plant Analysis, Vol. 30, No. 7-8, 1999, pp.1137-1152.

[12] T. Pare, E. G. Gregorich and B. H. Ellert, "Comparison of Soil Nitrate Extracted by Potassium Chloride and Adsorbed on an Anion Exchange Membrane in Situ," Communications in Soil Science and Plant Analysis, Vol. 26, No. 5-6, 1995, pp. 883-898. doi:10.1080/00103629509369341

[13] Applied Research Institute-Jerusalem, "Environmental Profile for the West Bank Volume 2: Jericho District," Applied Research Institute-Jerusalem, Bethlehem, 1995.

[14] L. A. Richards, "Diagnosis and Improvement of Saline and Alkali Soils," U.S. Government Printing Office, Washington DC, 1954.

[15] J. F. van Staden and R. E. Taljaard, "Determination of Ammonia in Water and Industrial Effluent Streams with 
the Indophenol Blue Method Using Sequential Injection Analysis," Analytica Chimica Acta, Vol. 344, No. 3, 1997, pp. 281-289. doi:10.1016/S0003-2670(96)00523-5

[16] E. Ballesteros, A. Rios and M. Valcárcel, "Integrated Automatic Determination of Nitrate, Ammonium and Organic Carbon in Soil Samples," Analyst, Vol. 122, No. 4, 1997, pp. 309-313. doi:10.1039/A607849D

[17] F. Zhang, J. Niu, W. Zhang, X. Chen, C. Li, L. Yuan and J. Xie, "Potassium Nutrition of Crops under Varied Regimes of Nitrogen Supply," Plant Soil, Vol. 335. No. 1-2, 2010, pp. 21-34. doi:10.1007/s11104-010-0323-4

[18] P. Mäser, M. Gierth and J. I. Schroeder, "Molecular Mechanisms of Potassium and Sodium Uptake in Plants," Plant and Soil, Vol. 247, No. 1, 2002, pp. 43-54. doi:10.1023/A:1021159130729

[19] R. Setia, K. N. Sharma, P. Marschner and H. Singh, "Changes in Nitrogen, Phosphorous, and Potassium in a Long-Term Continuous Maize-Wheat Cropping System in India," Communications in Soil Science and Plant Analysis, Vol. 40, No. 21-22, 2009, pp. 3348-3366. doi:10.1080/00103620903325950

[20] Q. Zeng and P. Brown, "Soil Potassium Mobility and Uptake by Corn under Differential Soil Moisture Regimes," Plant and Soil, Vol. 221, No. 2, 2000, pp. 121-134. doi:10.1023/A:1004738414847

[21] J. Ryan, S. Garabet, K. Harmsen and A. Rashid, "A Soil and Plant Analysis Manual Adapted for the West Asia and North Africa Region," International Center for Agricultural Research in the Dry Areas, Aleppo, 1996.

[22] J.-L. Zhang, T. J. Flowers and S.-M. Wang, "Mechanisms of Sodium Uptake by Roots of Higher Plants," Plant Soil, Vol. 326, No. 1-2, 2010, pp. 45-60. doi:10.1007/s11104-009-0076-0

[23] M. Giese, Y. Z. Gao, S. Lin and H. Brueck, "Nitrogen Availability in a Grazed Semi-Arid Grassland Is Dominated by Seasonal Rainfall," Plant and Soil, Vol. 340, No. 1-2, 2010, pp.157-167. doi:10.1007/s11104-010-0509-9
[24] Z.-Y. Yuan and L.-H. Li, "Soil Water Status Influences Plant Nitrogen Use: A Case Study," Plant Soil, Vol. 301, No. 1-2, 2007, pp. 303-313. doi:10.1007/s11104-007-9450-y

[25] B. van Raij, J. A. Quaggio and N. M. da Silva, "Extraction of Phosphorus, Potassium, Calcium, and Magnesium from Soils by an Ion-Exchange Resin Procedure," Communications in Soil Science and Plant Analysis, Vol. 17, No. 5, 1986, pp. 547-566. doi: $10.1080 / 00103628609367733$

[26] S. M. Helali, H. Nebli, R. Kaddour, H. Mahmoudi, M. Lachaal and Z. Ouerghi, "Influence of Nitrate-Ammonium Ratio on Growth and Nutrition of Arabidopsis thaliana," Plant Soil, Vol. 336, No. 1-2, 2010, pp. 65-74. doi:10.1007/s11104-010-0445-8

[27] M. M. Wander, D. V. McCracken, L. M. Shuman, J. W. Johnson and J. E. Box, "Anion-Exchange Membranes Used to Assess Management Impacts on Soil Nitrate," Communications in Soil Science and Plant Analysis, Vol. 26, No. 15-16, 1995, pp. 2383-2390.

[28] P. Nesse, J. Grava and P. R. Bloom, "Correlation of Several Tests for Phosphorous with Resin Extractable Phosphorous for 30 Alkaline Soils," Communications in Soil Science and Plant Analysis, Vol. 19, No. 6, 1988, pp. 675689.

[29] S. V. Karmarkar, "Quick Ion Chromatographic Determination of Sulfate Alone in Soil Extracts and Natural Waters," Communications in Soil Science and Plant Analysis, Vol. 27, No. 3-4, 1996, pp. 843-852.

[30] H. D. Foth, "Fundamentals of Soil Science," John Wiley \& Sons, New York, 1978.

[31] R. J. Haynes, "Effects of Soil Acidification on the Chemical Extractability of Fe, $\mathrm{Mn}, \mathrm{Zn}$ and $\mathrm{Cu}$ and the Growth with Micronutrient Uptake of Highbush Blueberry Plants," Plant and Soil, Vol. 84, No. 2, 1985, pp. 201-212. doi:10.1007/BF02143184 